УДК 796.8

https://doi.org/10.36906/FKS-2021/20

Ворожейкин А.В.

ORCID ID: 0000-0002-9289-5272, канд. пед. наук

Калининградский институт управления

г. Калининград, Россия

\title{
МОТИВАЦИЯ К СПОРТИВНОЙ ДЕЯТЕЛЬНОСТИ ВЫСОКОКВАЛИФИЦИРОВАННЫХ СПОРТСМЕНОК РУКОПАШНОГО БОЯ
}

Аннотация. В статье рассматривается проблема психологической подготовки спортсменок рукопашного боя, в частности исследована мотивация спортивной деятельности высококвалифицированных спортсменок рукопашного боя. Полученные в ходе исследования результаты свидетельствуют о необходимости научно-теоретического обоснования методики формирования мотивации на начальном этапе спортивной подготовки, способствующей психологической поддержки становления психологического пола спортсменок.

Ключевые слова: рукопашный бой, мотивация, мотив, цель, потребность.

Vorozheikin A.V. ORCID ID: 0000-0002-9289-5272, Ph.D. Kaliningrad Institute of Management Kaliningrad, Russia

\section{MOTIVATION TO SPORTS ACTIVITIES OF HIGHLY QUALIFIED HAND-TO-HAND FIGHT ATHLETES}

Annotation. The article deals with the problem of psychological training of female athletes in handto-hand combat, in particular, the motivation of sports activity of highly qualified female athletes in hand-to-hand combat is investigated. The results obtained in the course of the study indicate the need for a scientific and theoretical substantiation of the methodology for the formation of motivation at the initial stage of sports training, which contributes to psychological support for the formation of the psychological sex of athletes.

Keywords: hand-to-hand combat, motivation, motive, goal, need.

Актуальность. В современном спорте смешанные единоборства по своей популярности находятся на лидирующих позициях. Ранее культивируемый вид спорта только в Бразилии и США, постепенно завоевал зрительскую аудиторию в Европе. Благодаря широкой компании, проведенной по раскрутке таких промоушенов MMA как UFC, Belator, LFA, PFL и др. смешанные единоборства стали очень популярны в широких массах. По мнению экспертов в финансовом плане через несколько лет ММА способен затмить бокс.

Помимо мужских поединков на сегодняшний день в программе соревнований по единоборствам все чаще и чаще появляются женщины. По общему мнению специалистов, проводимая на западе ударная рекламная деятельность женских поединков промоушенов ММА накладывает отпечаток на популяризацию женских видов единоборств в целом. Заметен значительный приток спортсменок разного возраста в единоборства и особенно спортсменок юного возраста [1, с. 93].

Одним из единоборств, пользующимся широкой популярностью у женщин является рукопашный бой. Несмотря на то, что женская дисциплина рукопашного боя официально 
совсем недавно включена в программу соревнований в настоящее время проводятся соревнования самого высокого уровня с участием всех возрастных групп спортсменок.

Если буквально несколько лет назад Российские спортсмены с большим перевесом одерживали победы в командном зачете на всех Международных соревнованиях как среди мужчин, так и среди женщин, то сегодня эти победы даются уж не так просто, а уровень конкуренции в женской дисциплине рукопашного боя и вовсе зашкаливает.

С учетом выше обозначенного на сегодняшний день актуальным является разработка и обоснование эффективных подходов к тренировке спортсменок-рукопашниц различной спортивной квалификации. Учитывая то, что одним из ключевых факторов, определяющим способность спортсмена к профессиональному росту и высокой результативности является мотивация, учет мотивов спортивной деятельности является одной из приоритетных задач при планировании многолетней спортивной тренировки [2, с. 155].

Вопросы мотивации мужчин в видах спорта группы единоборств являются относительно изученными и имеются результаты научных исследований: в боксе [7, с. 11].

В свою очередь доказано, что у спортсменов мужского и женского пола существует ряд как общих, так и отличительных черт в мотивации к спортивной деятельности и их проявление на различных этапах подготовки неодинаково [3, с. 109].

Однако, не смотря имеющиеся научные исследования, особенности мотивации женщин в таком виде спорта как рукопашный бой можно обоснованно считать мало исследованным аспектом в общей системе их многолетней подготовки. Таким образом, противоречие между требованиями, предъявляемыми к уровню подготовленности спортсменок рукопашного боя с одной стороны и отсутствием научно-теоретических исследований по изучению мотивов спортивной деятельности квалифицированных спортсменок рукопашного боя с другой определило актуальность данного исследования.

Целью исследования являлось изучить мотивацию спортивной деятельности высококвалифицированных спортсменок рукопашного боя. К исследованию было привлечено 10 квалифицированных тренеров и 20 спортсменок ОФРБ Калининградской области. В программу исследования входили следующие методы: беседы со спортсменками различной квалификации и их тренерами, опрос, анкетирование, экспертная оценка. В исследовании использовались психодиагностические стандартизированные методики оценки мотивации спортсменов (опросники Реана А.А., Шаболтас А.В., Тропникова В.И., Бабушкина Е.Г.).

Мотивация спортивной деятельности формируется у спортсмена в условиях многолетней тренировки и участия в соревнованиях. На протяжении спортивной карьеры роль конкретных мотивов в стимулировании активности спортсмена меняется, и для каждого этапа спортивной карьеры характерны свои доминирующие мотивы [9, с. 98].

Мотивация достижения успеха и мотивация избегания неудач - два аспекта мотивации которые приняты выделять в спортивной деятельности. Для определения соотношения стремления к успеху и избегания неудачи у девушек занимающихся рукопашным боем на различных этапах спортивной подготовки применялась методика А.А. Ренна.

Как можно заметить по результатам анкетирования у респондентов в группах совершенствования и высшего спортивного мастерства лишь у одной спортсменки диагностирована мотивация боязни неудачи и у двух мотивационный полюс ярко не выражен (рис. 1).

По мнению опрошенных тренеров, будучи гендерно специфичным видом спорта некоторые стереотипы, связанные с излишней жесткостью соревновательной деятельностью в контактных видах единоборств сформированы и откладывают свой отпечаток на спортивную подготовку на начальных ее этапах. 


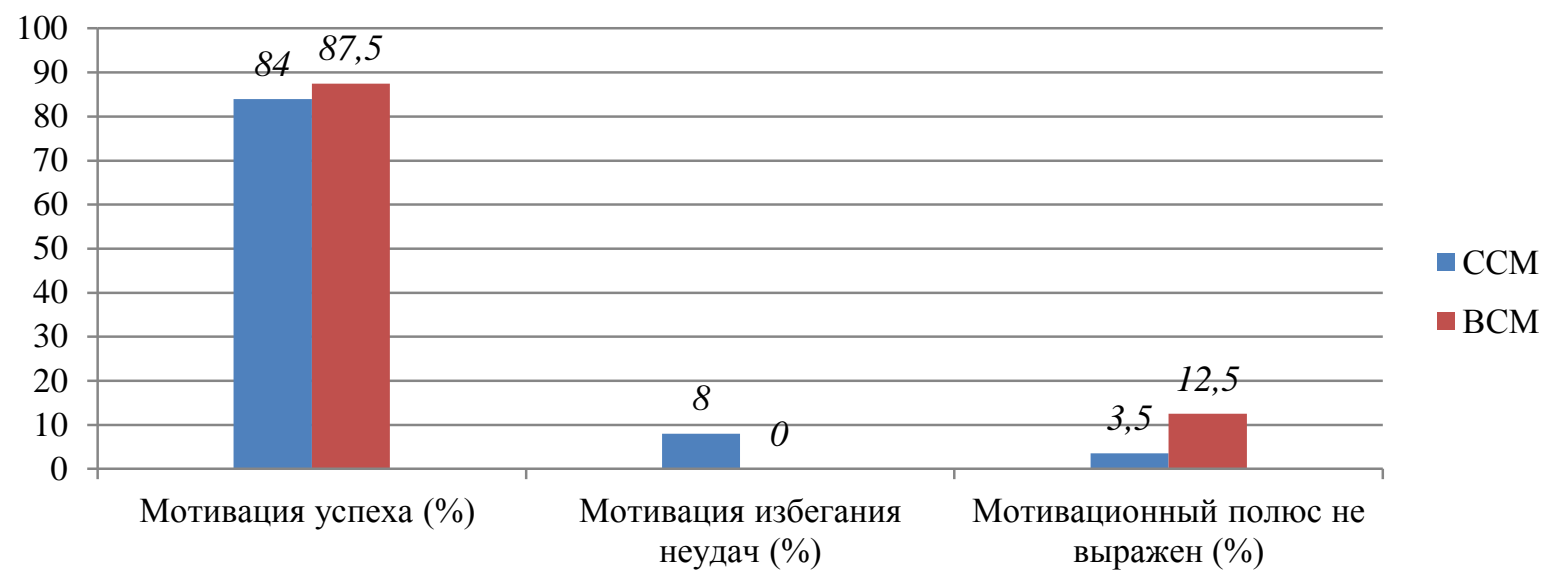

Рис. 1. Стремления к успеху и избегания неудачи у высококвалифицированных спортсменок занимающихся рукопашным боем

По их мнению, лишь к этапу совершенствования и высшего спортивного мастерства спортсменки психологически адаптируются к специфическим условиям тренировочной и соревновательной деятельности, появляется желание достичь каких-либо успехов в осуществляемой деятельности. На формирование мотивов оказывает специфика спортивной деятельности, они изменяются и преобразуются под влиянием обстоятельств, других спортсменов, оценки собственных действий и поступков, а так же целенаправленной воспитательной работы в процессе спортивного совершенствования. Таким образом, формирование мотивов зависит от стадии профессионализации и становления личности спортсмена [1, с. 165].

Для выявления доминирующих мотивов занятий девушками рукопашным боем на различных этапах спортивной подготовки использовалась методика А.В. Шаболтас (Рисунок 2).

$\because \mathrm{CCM} \backsim \mathrm{BCM}$

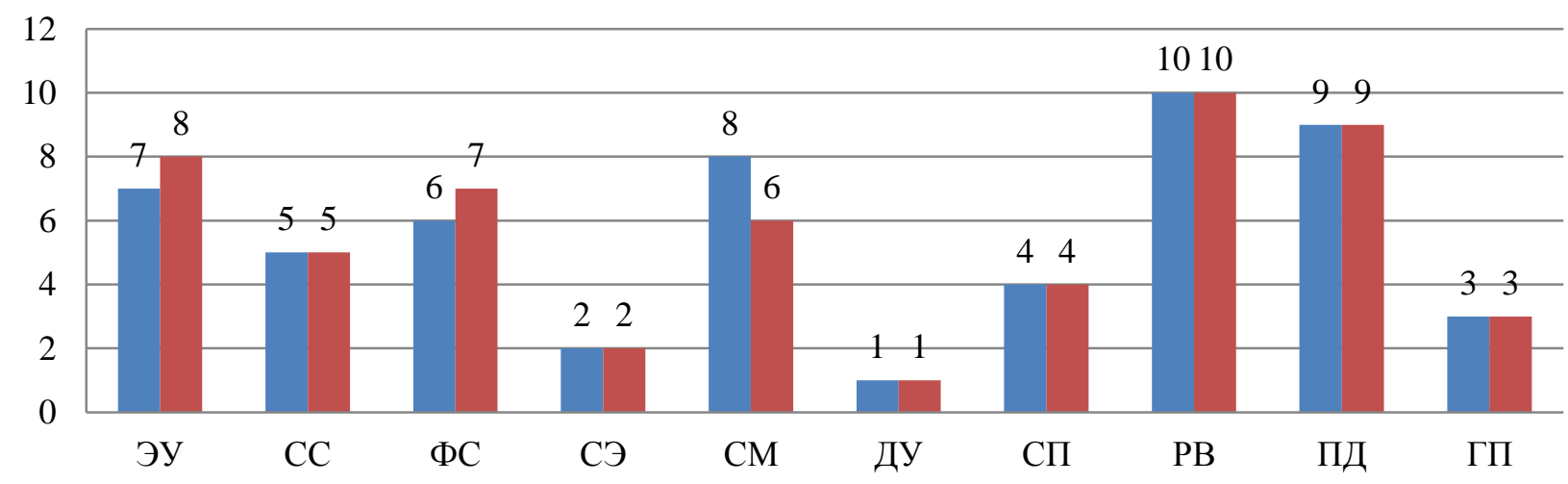

Рис. 2. Мотивы спортивной деятельности у высококвалифицированных спортсменок занимающихся рукопашным боем

Как можно заметить наиболее значимыми мотивами спортивной деятельности для спортсменок рукопашного боя на этапе спортивной специализации и высшего спортивного мастерства являются: мотивы достижения в спорте, социально-эмоциональный, гражданскопатриотический и спортивно-познавательный мотив. 
По результатам диагностики установлено, что на данных этапах заметно стремление спортсменок к улучшению личных спортивных результатов, получению спортивного звания, познанию содержания спортивной тренировки, изучению теоретических аспектов и методических принципов, освоение техники и тактики. Стремление к высоким результатам и активная соревновательная деятельность формирует гражданскую ответственность, ответственность перед тренером и престиж клуба, коллектива, города.

Мотивы социального самоутверждения, социально-моральный мотив, мотив физического самоутверждения не так ярко проявляются у спортсменок исследуемой группы, а рационально - волевой и мотив подготовки к профессиональной деятельности как оказалось наименее значимы. Для уточнения полученных в ходе анкетирования данных дополнительно проводилось анкетирование квалифицированных тренеров осуществляющих спортивную подготовку девушек в рукопашном бое. По мнению опрошенных на этапах совершенствования и высшего спортивного мастерства у спортсменок ярко выражено стремление проявить себя, занятия спортом и достигаемые при этом успехи рассматриваются и переживаются с точки зрения личного престижа, уважения знакомыми, зрителями. По мнению тренеров проводимая на западе ударная рекламная деятельность представителей смешанных единоборств откладывает отпечаток на формирование мотива социального самоутверждения. Взрослые спортсменки с определенными предпосылками к высоким достижениям, либо уже имея их понимают, что за счет спортивной деятельности можно получить популярность и материальные блага, повысить свою значимость не только в спортивной, но и социальной среде. Для выяснения степени важности различных причин побуждающих спортсменок заниматься рукопашным боем проводилось анкетирование по методике В.И. Тропникова (рис. 3).

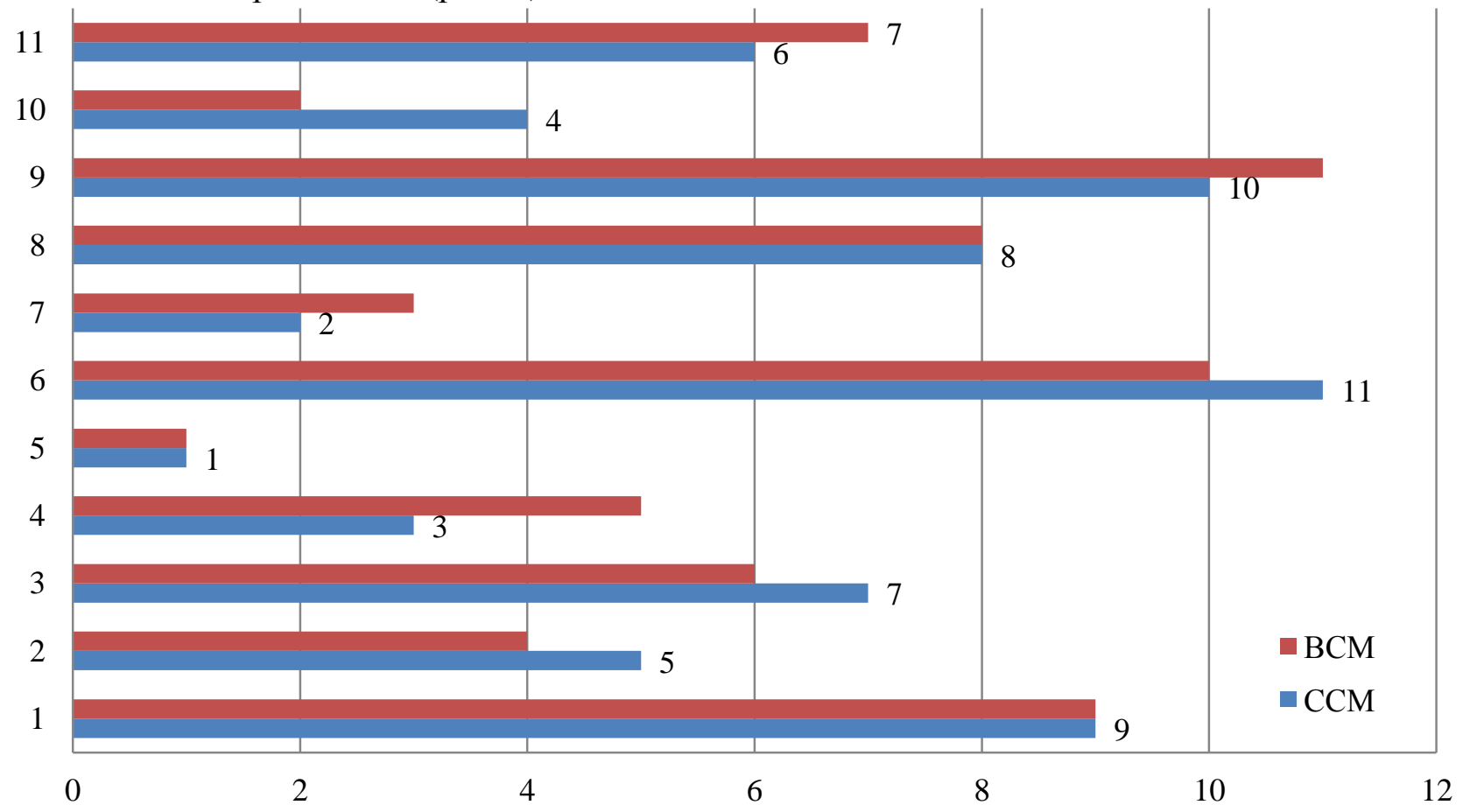

Рис. 3. Степень важности различных мотивов у высококвалифицированных спортсменок занимающихся рукопашным боем: 1- Общение; 2 - Познание; 3 - Материальные блага; 4 - Развитие характера и психических качеств; 5 - Физическое совершенствование;

6 - Улучшение самочувствия, здоровья; 7 - Эстетические удовольствия;

8 - Приобретение полезных для жизни умений; 9 - Потребность в одобрении; 10 - Повышение престижа, желание славы; 11 - Коллективистская направленность 
Как можно заметить к наиболее значимым мотивам в группах совершенствования и высшего спортивного мастерства относятся физическое совершенствование, эстетическое удовольствие и поиск острых ощущений, повышение престижа, желание славы, познания. В свою очередь менее выражены потребность в одобрении, улучшения самочувствия и здоровья, общения. Для успешной тренировочной деятельности важно чтобы у спортсмена был интерес к осуществляемой тренировочной деятельности [5, с. 221].

Данный показатель оценивался по методике Г.Д. Бабушкина (Рисунок 4).

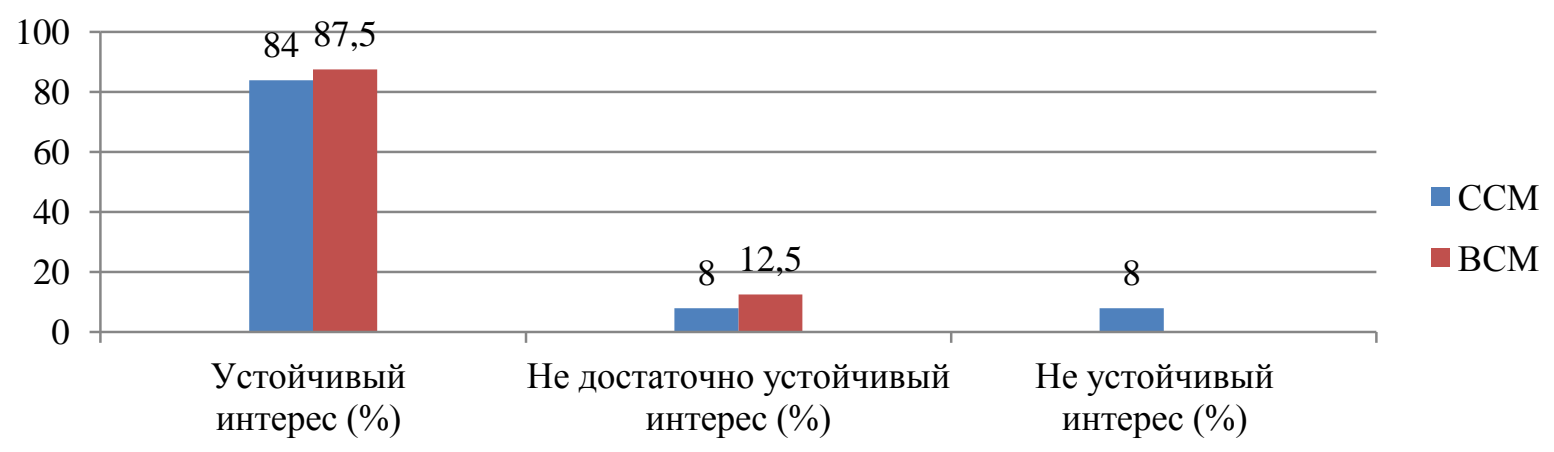

Рис. 4. Уровень устойчивости интереса у высококвалифицированных спортсменок занимающихся рукопашным боем

По результатам анкетирования установлено, что в группе совершенствования и высшего спортивного мастерства выявлен устойчивый интерес к занятиям рукопашным боем, средний показатель 31,3 и 31,2 соответственно. Абсолютно всем опрошенным нравиться выступать и побеждать на соревнованиях, а побудительной силой для тренировок является желание высоких результатов.

Заключение. По результатам обработки данных исследования установлено для спортсменок групп совершенствования и высшего спортивного мастерства характерен:

- высокий уровень мотивации достижения успеха. Помимо этого выявлен устойчивый интерес к занятиям рукопашным боем, в основе которого лежит желание выступать и побеждать на соревнованиях, достигать высоких результатов;

- мотив социального самоутверждения на данных этапах спортивной подготовки доминирует. Квалифицированные спортсменки понимают, что за счет спортивной деятельности можно получить популярность и материальные блага, повысить свою значимость не только в спортивной, но и социальной среде.

Выводы. Таким образом, выявленные в ходе исследования обстоятельства свидетельствуют о необходимости научно-теоретического обоснования методики формирования спортивной мотивации у юных спортсменок рукопашного боя, направленной на формирование спортивного самоопределения и способствующей психологической поддержки становления психологического пола спортсменок.

\section{Литература}

1. Ворожейкин А.В., Фадеева В.В., Волков А.П. Рукопашный бой как самостоятельный вид спорта, ретроспектива и перспективы // Вестник Калининградского филиала СанктПетербургского университета МВД России. 2019. №4. С. 92-96. 
2. Ворожейкин А.В. Волков А.П., Тюпа П.И. Анализ современных тенденций научных исследований по виду спорта «Рукопашный бой». На основе обзора диссертационных работ // Известия Балтийской государственной академии рыбопромыслового флота: психологопедагогические науки. 2020. №1(51). С. 154-159.

3. Ворожейкин А.В., Врачинская Т.В., Тюпа П.И., Волков А.П. К вопросу научнотеоретического обоснования многолетней спортивной подготовки женщин в рукопашном бое // Известия тульского государственного университета. Физическая культура. Спорт. 2020 . №9. C. $105-114$.

4. Бабушкин Е.Г. Формирование спортивной мотивации у боксеров на этапе начальной подготовки: Автореф. ... канд. пед. наук. Омск, 2000.

5. Бабушкин Г.Д. Психология физической культуры и спорта: учебник для высших физкультурных учебных заведений. Омск: СибГУФК, 2007. 270 с.

6. Ганоль А.С. Гендерные особенности и структура мотивации выбора экстремальных видов спорта: Автореф. дис. ... канд. пед. наук. СПб., 2011.

7. Ильина Н.Л. Динамика мотивации на протяжении спортивной карьеры: Автореф. дис. ... канд. пед. наук. СПб., 1998.

(C) Ворожейкин A.B., 2021 